\title{
STUDENT'S PERCEPTION ABOUT MODULAR TEACHING AND VARIOUS INSTRUCTIONAL STRATEGIES IN THE SUBJECT OF OBSTETRICS AND GYNECOLOGY.
}

\author{
1. MBBS, MCPS, FCPS \\ Assistant Professor \\ Obstetrics and Gynecology \\ University Medical and \\ Dental College, Faisalabad. \\ 2. MBBS, MCPS, FCPS \\ Professor \\ Obstetrics and Gynecology \\ University Medical and \\ Dental College, Faisalabad. \\ 3. MBBS, FCPS \\ Associate Professor \\ Obstetrics and Gynecology \\ University Medical and \\ Dental College, Faisalabad. \\ 4. MBBS, FCPS \\ Assistant Professor \\ Obstetrics and Gynecology \\ University Medical and \\ Dental College, Faisalabad. \\ 5. MBBS, FCPS \\ Associate Professor \\ Department of Internal Medicine \\ Aziz Fatima Medical and \\ Dental College, Faisalabad. \\ Correspondence Address: \\ Dr. Umber Fatima \\ Department of Obstetrics and \\ Gynecology \\ University Medical and \\ Dental College, Faisalabad. \\ umberfatima158@gmail.com \\ Article received on: \\ 21/01/2019 \\ Accepted for publication: \\ 25/08/2019
}

\section{INTRODUCTION}

In recent past, many modifications have been introduced in the field of medical education. There is a revolutionary shift from traditional lecture based teaching to the use of more interactive, student focused teaching strategies and competency based learning. Didactic teaching model is still the most popular method in many institutions despite its inherent limitation of transfer of fragmented knowledge, passive learning, poor long term retention of concepts and difficulty in practical application in real life situations. ${ }^{1,2}$ Medical educationists have a strong disapproval for conventional teaching methods and many have proposed implementation of more effective strategies to improve critical thinking and problem solving skills of the students. ${ }^{3}$ Health authorities

\begin{abstract}
Umber Fatima1', Mubashra Naz ${ }^{2}$, Humaira Zafar ${ }^{3}$, Anees Fatima ${ }^{4}$, Rizwan Rasool Khan ${ }^{5}$
ABSTRACT: Many modifications have been introduced in the field of medical education in A sth a shift from didactic to more student focused teaching strategies. Modular Gynecology in 2018 session. Objectives: To determine the students' perception about modular teaching and various instructional strategies through feedback in the subject of Obstetrics and Gynecology at undergraduate level. Study Design: Cross sectional study. Setting: University Medho: Eight modules were designed in the subject of obstetrics and gynecology for final (Interpretation of collected data was performed on SPSS 20. Results: Total 136 sessions and prom $97.1 \%$ and $94.85 \%$ ) respectively by the students. Conclusion: Modular teaching was found to be an interesting and a useful teaching - learning experience by majority of students. Almost all students showed positive acceptance for various teaching methods. Students' feedback was also useful in identifying course components that need improvement so that appropriate
\end{abstract} Key words: $\quad$ Feedback, Modular Teaching, Satisfaction, Students.

Article Citation: Fatima U, Naz M, Zafar H, Fatima A, Khan RR. Student's perception about Modular teaching and various instructional strategies in the subject of Obstetrics and Gynecology. Professional Med J 2020; 27(1):40-45. DOI: 10.29309/TPMJ/2020.27.1.3162

also recommend that medical training should be based on integration of knowledge, scientific inquiry, analysis and subsequent ability to drive conclusions. ${ }^{4}$ Current challenge is to determine a suitable curriculum and teaching methods which allow better application of knowledge and clinical skills by the medical students.

Self-directed and problem based learning (PBL), small group discussions and mini seminars are popular learning approaches and widely implemented in medical education. ${ }^{5}$ Literature suggests that these methods are associated with better development of cognitive and psychomotor skills of learners. ${ }^{6}$ This is the basis for global recommendation of integration, construction of modules and blended teaching at undergraduate 
level in medical colleges. Modular teaching is an instructional method which involves self-directed learning of defined objectives by using different activities. Modules also provide the opportunity to use various interactive modalities which seems to be more attractive to students and facilitate active learner's participation. ${ }^{7}$

The medical training in Pakistan is still in the process of transformation to meet the international standards of healthcare. Local health authorities have highlighted the need to replace traditional classroom teaching with more student focused approaches..$^{8,9}$ However, a few institutions have adopted such strategies primarily due to lack of resources and nominal educational budgets.

Evaluation of any curricular program is essential to determine its effectiveness and students' feedback is an indirect and inexpensive method for this purpose. ${ }^{10}$ It is not only important for students but formal students' evaluation of modules can provide an opportunity for the teachers as well, to ascertain the effectiveness of a course. ${ }^{11}$ In developing countries like Pakistan, formal feedback is neither provided to, nor obtained from students. Therefore limited data is available about students' perception for currently employed teaching-learning methodologies at undergraduate level.

Integrated modular teaching has been well accepted worldwide, however enduring any curricular innovation should be judged by all stakeholders including learners before its generalized implementation. Effectiveness of a curriculum may be evaluated indirectly by student's satisfaction and their opinion about positive and negative aspects of a program. Student's acceptance and readiness is an integral component for successful implementation and future continuation of any curricular change. Present study was all the more relevant because our students were familiar to traditional lecture based teaching and had their first ever experience of modular teaching. This intervention was made in an attempt to identify the students' perspective and to plan appropriate measures for future improvement of the modules.

\section{METHODS}

It was a cross sectional study, conducted at University Medical and Dental College, Faisalabad from January 2018 to October 2018 after approval by the institutional ethical committee. A total of 140 students of final year MBBS class were included in the study after informed consent. The curriculum of Obstetrics and Gynecology was designed as eight modules with predefined objectives. Each module was of six to eight week duration depending upon the content to be delivered. These modules were conducted over a period of ten months. Different teaching methods were used to teach the content. A questionnaire was designed to collect feedback. Students' response about content delivery and activities of modules was recorded according to five point Likert's scale rating as strongly agree (score 1), agree (score 2), no response (score 3), disagree (score 4) and strongly disagree (score 5) in section 1 of questionnaire. In section 2 , students' perception about process of modular teaching was recorded as three point scale consisting of agree, disagree and no response. Feedback regarding different teaching methods was also recorded as method being useful, not useful and no response.

SPSS version 20 was used for interpretation of collected data. Qualitative variables were calculated as frequencies and percentages. Group means and standard deviations were also calculated. Testing for significance of mean was calculated and test value was 1.82.

\section{RESULTS}

Total 140 students participated in this study but only 136 returned back properly filled questionnaire.

Modular teaching was appreciated as an effective method by students. For descriptive purpose, rating of strongly agree and agree was taken as one. Overall, majority of students 127(93.4\%) were satisfied with module delivery and activities of modules (Table-I).

Students were most satisfied by clear learning objectives, organized delivery, relevance of assignments and usefulness of handouts. Table- 
Il shows participants response for process of modular teaching and educational impact. The ability of developing independent thinking by modular teaching was perceived by 132 (97.1\%) participants. Improved teacher-student interaction was well appreciated impact by a significantly larger proportion of students, 129 (94.85\%) in modular system.

\begin{tabular}{|c|c|c|c|c|c|c|}
\hline Variables & $\begin{array}{c}\text { Strongly } \\
\text { Agree }\end{array}$ & Agree & $\begin{array}{c}\text { Not } \\
\text { Applicable }\end{array}$ & Disagree & $\begin{array}{l}\text { Strongly } \\
\text { Disagree }\end{array}$ & Mean \pm SD \\
\hline $\begin{array}{l}\text { There was a balance between } \\
\text { teaching - learning activities }\end{array}$ & $\begin{array}{c}59 \\
(43.4 \%)\end{array}$ & $\begin{array}{c}66 \\
(48.5 \%)\end{array}$ & $\begin{array}{c}2 \\
(1.5 \%)\end{array}$ & $\begin{array}{c}5 \\
(3.7 \%)\end{array}$ & $\begin{array}{c}4 \\
(2.9 \%)\end{array}$ & $1.74 \pm 0.894$ \\
\hline The handouts were helpful & $\begin{array}{c}56 \\
(41.2 \%)\end{array}$ & $\begin{array}{c}68 \\
(50 \%)\end{array}$ & $\begin{array}{c}2 \\
(1.5 \%)\end{array}$ & $\begin{array}{c}6 \\
(4.4 \%)\end{array}$ & $\begin{array}{c}4 \\
(2.9 \%)\end{array}$ & $1.78 \pm 0.908$ \\
\hline $\begin{array}{l}\text { The workload associated with } \\
\text { assignments was manageable }\end{array}$ & $\begin{array}{c}49 \\
(36 \%)\end{array}$ & $\begin{array}{c}64 \\
(47.1 \%)\end{array}$ & $\begin{array}{c}5 \\
(3.7 \%)\end{array}$ & $\begin{array}{c}13 \\
(9.6 \%)\end{array}$ & $\begin{array}{c}5 \\
(3.7 \%)\end{array}$ & $1.98 \pm 1.057$ \\
\hline The assignments were relevant & $\begin{array}{c}52 \\
(38.2 \%)\end{array}$ & $\begin{array}{c}75 \\
(55.1 \%)\end{array}$ & $(1.5 \%)$ & $\begin{array}{c}4 \\
(2.9 \%)\end{array}$ & $\begin{array}{c}3 \\
(2.2 \%)\end{array}$ & $1.76 \pm 0.812$ \\
\hline $\begin{array}{l}\text { The feedback I received on my } \\
\text { progress was helpful }\end{array}$ & $\begin{array}{c}53 \\
(39 \%)\end{array}$ & $\begin{array}{c}67 \\
(49.3 \%)\end{array}$ & $\begin{array}{l}2 \\
(1.5 \%)\end{array}$ & $\begin{array}{c}9 \\
(6.6 \%)\end{array}$ & $\begin{array}{c}5 \\
(3.7 \%)\end{array}$ & $1.87 \pm 0.995$ \\
\hline The tutors were helpful & $\begin{array}{c}60 \\
(44.1 \%)\end{array}$ & $\begin{array}{c}64 \\
(47.1 \%)\end{array}$ & $\begin{array}{c}2 \\
(1.5 \%)\end{array}$ & $\begin{array}{c}7 \\
(5.1 \%)\end{array}$ & $\begin{array}{c}3 \\
(2.2 \%)\end{array}$ & $1.74 \pm 0.894$ \\
\hline $\begin{array}{l}\text { Overall, I was satisfied with } \\
\text { module system }\end{array}$ & $\begin{array}{c}70 \\
(51.5 \%)\end{array}$ & $\begin{array}{c}57 \\
(41.9 \%)\end{array}$ & $\begin{array}{c}2 \\
(1.5 \%)\end{array}$ & $\begin{array}{c}4 \\
(2.9 \%)\end{array}$ & $\begin{array}{c}3 \\
(2.2 \%)\end{array}$ & $1.63 \pm 0.843$ \\
\hline
\end{tabular}

Table-I. Students' response regarding content and activities of modules.
Regarding different instructional methods(TableIII), small group discussion(97.1\%) and case based studies(97.7\%) were considered most useful methods of teaching followed by problem based learning(94.8\%) and power point presentations (94.9\%) by the students.

\begin{tabular}{|l|c|c|c|}
\hline \multicolumn{1}{|c|}{ Variables } & Agree & Disagree & No Response \\
\hline Stimulated interest in subject & $119(87.5)$ & $16(11.76)$ & $1(0.74)$ \\
\hline Improved Teacher student interaction & $129(94.84)$ & $5(3.67)$ & $2(1.48)$ \\
\hline Development of independent thinking & $132(97.1)$ & $4(2.9)$ & 0 \\
\hline Preparation for critical thinking & $116(85.3)$ & $16(11.8)$ & $4(2.9)$ \\
\hline Improved sense of team work & $75(55.1)$ & $60(44.11)$ & $1(0.74)$ \\
\hline
\end{tabular}

\section{Table-II. Response regarding process of modular teaching $\mathbf{N}=136$ (\%)}

\begin{tabular}{|l|c|c|c|}
\hline \multicolumn{1}{|c|}{ Variables } & Useful & Not Useful & No Response \\
\hline Tutorials & $86(63.23 \%)$ & $49(36.03 \%)$ & $1(0.74 \%)$ \\
\hline Small group discussion & $132(97.1 \%)$ & $04(2.9 \%)$ & 0 \\
\hline Problem based learning & $129(94.85 \%)$ & $05(3.68 \%)$ & $2(1.47 \%)$ \\
\hline Self directed learning & $120(88.2 \%)$ & $13(9.6 \%)$ & $3(2.2 \%)$ \\
\hline Hands on practice on manikins & $122(89.7 \%)$ & $11(8.1 \%)$ & $3(2.2 \%)$ \\
\hline Case based learning & $133(97.79 \%)$ & $01(0.74 \%)$ & $2(1.47 \%)$ \\
\hline Use of group assignments & $123(90.44 \%)$ & $12(8.82 \%)$ & $1(0.74 \%)$ \\
\hline Use of multimedia and power point & $129(94.9 \%)$ & $04(2.9 \%)$ & $3(2.2 \%)$ \\
\hline
\end{tabular}

Table-III. Response regarding different teaching strategies. $\mathrm{N}=136$ (\%) 


\section{DISCUSSION}

Although the concept of modules is not new among educationists, still it is not widely practiced in medical institutions of Pakistan. Based on PM \& DC guidelines, University Medical and Dental College has introduced the pilot project of modular system for the subject of obstetrics and gynaecology to mark a shift towards more learner focused teaching approach in an attempt to meet the international standards.

Effectiveness of a curriculum depends upon successful educational environment and necessary involvement and enthusiasm of students. In the present study, 93.4\% students were satisfied with modular system and the results are supported by a similar study in which majority of students (86.8\%) felt that modular teaching was a useful and interesting learning experience. ${ }^{12}$ A recent research comparing faculty and students' perception for integrated modules showed acceptance rate of $93 \%$ which is very close to our findings. ${ }^{13}$ Many studies attest that modular style is associated with increased brainstorming and focused learning as compared to didactic teaching. ${ }^{14}$ Learners can be exposed to various teaching methodologies in modules with positive students' acceptance. ${ }^{7}$

Active learning strategies are not only supported by adult learning theories but local accreditation authorities also demand to redefine medical programmes so that students have an opportunity to develop competencies related to professionalism and medical ethics. Education experts advocate that students are more focused and motivated by learner oriented teaching when compared to traditional methods. ${ }^{15}$ Various interactive instructional strategies were used in current study to deliver content and respondents in present study agreed that these strategies increased their interest in subject and stimulated independent thinking abilities with better teacher $\square$ student interaction. In a study by Preeti P Yadav and colleagues, $75 \%$ of students reinforce similar findings. ${ }^{16}$ Another study demonstrates that active learning modules are associated with better understanding of abstract concepts (77\%) and more teacher $\square$ student interaction. ${ }^{17}$ In a published research, 94\% students reported that interactive sessions facilitate interest in subject and motivate for more study. ${ }^{18}$ According to $95 \%$ participants of a study, interactive lecture modules were associated with significant improvement in understanding of subject and better practical skills. ${ }^{19}$ Many researchers emphasize that interactive environment increases the critical thinking ability and attention span of learner with improved learning outcomes. ${ }^{20}$

Tutorial is a type of remedial teaching in which individual considerations are taken into account. A study by Shandana Ali Khan and coworkers shows that $72.4 \%$ students appreciated tutorials as a useful teaching method. ${ }^{21}$ Although $63 \%$ students have appreciated the usefulness of tutorials in the present study, still $36 \%$ suggested it as not useful. Majority of students raised concerns regarding unequal teacher attention and poor group management. Large class size in medical colleges is a growing challenge for effective teaching. Dividing class in small groups is considered to be associated with better understanding of difficult concepts and facilitate collaborative learning skills. In present study, a large proportion of students reported that small group discussions (SGD) were very beneficial to build self-confidence. Students opinioned that small group discussions promote more teacher-student communication which boost to ask questions and explanations. The same have been emphasized by another study in which $62.5 \%$ students strongly agreed that small group sessions helped to clear difficult concepts. ${ }^{22}$

Problem based learning (PBL) is an educational approach which sharpens students' clinical reasoning and analytical abilities with appropriate application of knowledge in real life situations. In the present study, 94\% students had positive attitude for problem based learning and $88 \%$ were motivated for self directed learning which is consistent with findings of study by Sultan Ayoub Meo where $80 \%$ students were in the favor of PBL. ${ }^{23}$ Same results are recorded by other researchers who noted that self-directed learning and decision making skills are improved in PBL sessions by creating an interesting teaching 
environment. ${ }^{24}$ In another study, $86 \%$ medical students valued PBL sessions as a very useful teaching strategy. ${ }^{25,26}$

Case based teaching (CBL) promotes the contextualized learning of students in the background of patients. Students valued this strategy very positively in our study. Case based learning (CBL) is strongly favored by students in many other studies. ${ }^{27}$

\section{CONCLUSION}

Majority of students were satisfied with modular teaching. They positively perceived that process was associated with better understanding of subject and improved concept of team work. This study supports the logical approach that modular teaching strategy can be incorporated effectively at undergraduate level. However further research is needed in this area on local population before its generalized application.

\section{Copyright@ 25 Aug, 2019.}

\section{REFERENCES}

1. Sadeghi R, Sedaghat M M, Ahmadi S F. Comparison of the lecture and blended teaching methods on students' learning and satisfaction. J Adv Med Educ Prof. 2014; 2(4):146-150.

2. Ramnan $J$ C, Pound D L. Advances in medical education and practice: Student perceptions of the flipped classroom. Adv Med Educ Pract. 2017; 8:63-73

3. Ahmad N H. Students' Feedback: An assessment tool for teaching and learning. J Surg Pak. 2015 JulySeptember; 20(3): 106 $\square 10$.

4. Joseph N, Rai S, Madi D, Bhat K, Kotian M S, Kantharaju $S$. Problem- based learning as an effective tool in Community Medicine: initiative in a private medical college of a developing country. Indian J Community Med. 2016; $41(2)$ : 133-40

5. Qiao Q Y, Shen J, Liang X, Ding S, Chen Y F, Shao L, et al. Using cognitive theory to facilitate medical education. BMC Med Educ. 2014; 14: 79

6. Kadmon G, Schmidt J, De Cono N, Kadmon M. Integrative vs. Traditional learning from the student perceptive. GMS Z Med Ausbild 2011; 28(2): Doc 28
7. Karthikeyan K, Kumar A. Integrated modular teaching in dermatology for undergraduate students: $A$ novel approach. Indian Dermatol Online J 2014 Jul-Sep; 5(3): 266-70

8. Bushra Manzar, Nabeel Manzar. To determine the level of satisfaction among medical students of a public sector medical university regarding their academic activities. Manzar and Manzar BMC Rearch notes 2011, $4: 360$

9. Shafiq Z, Mufti S T, Qayum I. Role of clinical skill centre in undergraduate medical education: initial experience at Rehman Medical College Peshawar. J Pak Med Assoc. 2017, 67(1) / 73 76

10. Aggarwal M, Singh S, Sharma A, Singh P, Bansal P. Impact of structured feedback module in medical education: A questionnaire- and test score- based analysis. Int J Appl Basic Med Res 2016 Jul-Sep; 6(3): 220-25

11. Atta S I, ALQahtani N F. Matching medical students achievement to learning objectuves and outcomes: a paradigm shift from an implemented teaching module. Adv Med Educ Pract. 2018; 9: 227-33

12. Salama $M H$, Nour- Eldein $H$. Final year medical students' satisfaction with clinical education and family medicine module. Suez Canal University. Egypt. J Contemp Med Edu. 2016; 4(3): 113-19

13. Shehnaz I S, Sreedharan J, Gomathi G K. Faculty and students' perceptions of student experiences in a medical school undergoing curricular transition in the United Arab Emirates. Sultan Qaboos Univ Med J.2012 Feb; 12(1): 77-85

14. Chavda P, Pandya C, Solanki D, Dindod S. Is Dmodular" the to go for small group learning in community medicine in undergraduate clinical posting? Int $\mathrm{J}$ Appl Basic Med Res. 2016 Jul-Sep; 6(3): 211-14

15. Imafuku R, Siaki T, Kawakami C, Suzuki Y. How do students' perception of research and approaches to learning change in undergraduate research. Int J Med Educ. 2015; 6: 47-5

16. Yadav P P, Chaudhary M, Patel J, Shah A, Kantharia ND. Effectiveness of integrated teaching module in pharmacology among medical undergraduates. Int $\mathrm{J}$ Appl Basic Med Res. 2016; 6(3): 215-18

17. Tripathi K R, Sarkate V, Jalgaonkar V S, Rege N $N$. Development of active learning module in Pharmacology for small group teaching. Educ Health (Abingdon). 2015; 28(1): 46-51 
18. Jayakumar $\mathrm{N}$, Muthukumar $\mathrm{S}$, Kandasamy $\mathrm{M}$, Perception of medical students on usefulness of interactive lectures: can it be a welcome change? Int J Biomed Adv Res 2016; 7: 270- 3

19. Ramnan VLM, Raju S K. Study on effectiveness of integrated lecture module versus didactic lecture module. IORS Journal of Dental and Medical Sciences (IORS- JDMS) 2015; 14(1): 14-16

20. Datta R, Datta K, Venkatesh M D. Evaluation of interactive teaching for undergraduate medical students using a classroom interactive response system in India. Med J Armed Forces India. 2015; $71(3)$ : 239-245

21. Khan A S, Asadullah M, Naz S, Trends in medical education from traditional to integrated system: valued by first year MBBS students at a private college of Peshawar. Journal of medical education (JME). 2015; 1(1): 12-19

22. Hadimani P.C. Effectiveness of small group discussion in teaching biochemistry for undergraduate medical students. South East Asian Journal of Medical Education (SEAJME) 2014; 8(1): 77- 80
23. Meo AS, Undergraduate medical students' perception on traditional and problem based curricula: Pilot study. J Pak Med Assoc. 2014; 64(7): 775— 9.

24. Ibrahim E M, AL-Shahrani M A, Ebdalla E M, Abubakar M I, Mohamed E M. The effectiveness of Problembased learning in acquisition of knowledge. Soft skills during basic and preclinical sciences: Medical students' point of view. Acta Inform Med. 2018Jun; 26(2): $119 \square 24$

25. ALGDrees A A, Khalil M S, Irshad M, Abdulghani H M. Students' perception towards the problem based learning tutorial session in a system $\square$ based hybrid curriculum. Saudi Med J. 2015 March; 36(3): 341-48

26. Lee Y S, Yune J S, Im J S, Baek Y S. Students' perception of problem base learning tutorial sessions in a system- based hybrid curriculum. Saudi Med J 2016; $37(2): 217$

27. Bansal M, Manoj G. To introduce and measure the effectiveness of case based learning in physiology. Int J Res Med Sci 2017; 5(2): 437- 445

\begin{tabular}{|c|c|c|c|}
\hline \multicolumn{3}{|c|}{ AUTHORSHIP AND CONTRIBUTION DECLARATION } \\
\hline Sr. \# & Author(s) Full Name & \multicolumn{1}{|c|}{ Contribution to the paper } & Author(s) Signature \\
\hline 1 & Umber Fatima & $\begin{array}{l}\text { Corresponding author, Collection } \\
\text { \& assambly of data, drafting of } \\
\text { article. } \\
\text { Conception \& djesign, Statistical } \\
\text { expertise, article formation. } \\
\text { Critical revision of the article. }\end{array}$ \\
\hline 3 & Mubashra Naz & Anees Fatima & Composing of the paper. \\
\hline 5 & Rizwan Rasool Khan & Proof reading of paper. \\
\hline
\end{tabular}

